\title{
Şanlıurfa koşullarında yetiştirilen bazı salep türlerinin bitkisel özellikleri ve glukomannan içeriklerinin belirlenmesi
}

\section{Determination of the botanical properties and glucomannan contents of some salep species cultivated in Şanlıurfa conditions}

\author{
Sadullah ERTAŞ ${ }^{1^{*}}$ iD , Abdulhabip ÖZEL ${ }^{2}$ iD, Kaan ERDEN ${ }^{2}$ iD \\ ${ }^{1}$ Üniversitesi, Fen Bilimleri Enstitüsü, Tarla Bitkileri Anabilim Dalı, Şanlıurfa \\ ${ }^{2}$ Harran Üniversitesi, Ziraat Fakültesi, Tarla Bitkileri Bölümü, Şanlıurfa
}

To cite this article:

Ertaş, S., Özel, A. \& Erden, K. (2019). Şanlıurfa koşullarında yetiştirilen bazı salep türlerinin bitkisel özellikleri ve glukomannan içeriklerinin belirlenmesi. Harran Tarım ve Gıda Bilimleri Dergisi, 23(1): 39-46.

DOI: $10.29050 /$ harranziraat.406221

Address for Correspondence: Sadullah ERTAŞ

e-mail:

harranertas@gmail.com

Received Date:

19.03.2018

Accepted Date:

18.01.2019

(c) Copyright 2018 by Harran University Faculty of Agriculture. Available on-line
www.dergipark.gov.tr/harranziraat

This work is licensed under a Creative Commons Attribution-
Non Commercial Non Commercial
International License. öz

Bu araştırma, Şanlıurfa koşullarında bazı salep türlerinin (Ophrys lutea Cav., Serapias vomeracea (Burm. Fill.) Brig, Ophrys mammosa Desf., Ophrys umbilicata Desf. ve Orchis sancta L.) bitkisel özellikleri ve glukomannan içeriklerinin belirlenmesi amacıyla, 20162017 kışlık ürün yetiştirme döneminde, Harran Üniversitesi Ziraat Fakültesi, Osmanbey Kampüsü deneme arazisinde, tesadüf blokları deneme desenine göre, 3 tekrarlamalı olarak yürütülmüştür. Araştırmada, morfolojik gelişme dönemlerine bağlı olarak bitkilerde, yaprak genişliği ve boyu, yaprak sayısı, yumru sayısı, bitki boyu uzunluğu, çiçek sayısı ve glukomannan oranı özellikleri incelenmiştir. Araştırma sonucunda, bitki boyunun 9.71-24.33 cm, bitki başına çiçek sayısının 2.50-12.03 adet bitki ${ }^{-1}$, bitkide yaprak sayısının 2.10-5.16 adet bitki ${ }^{-1}$, yavru yumru sayısının 1.00-1.50 adet bitki ${ }^{-1}$, yaprak boyunun 2.82$9.34 \mathrm{~cm}$, yaprak eninin $1.33-1.95 \mathrm{~cm}$, bitki başına yumru veriminin $1.69-9.11 \mathrm{~g} \mathrm{bitki}^{-1}$ ve glukomannan oranının \%28.60-59.63 arasında değişim gösterdiği saptanmıştır. En yüksek yumru verimi elde edildiği Orchis sancta L. ve en yüksek glucomannan oranının saptandığı Serapias vomeracea (Burm Fill.) Brig., türlerinin Şanlıurfa koşullarında yetiştirilebileceği söylenebilir.

Anahtar Kelimeler: Orchidaceae, Salep orkidesi, Salep, Glukomannan

\section{ABSTRACT}

This research was carried out to determination of the some botanical properties and glucomannan contents of some salep species (Ophrys lutea Cav., Serapias vomeracea (Burm. Fill.) Brig, Ophrys mammosa Desf., Ophrys umbilicata Desf. and Orchis sancta L.) under Şanlıurfa conditions, in 2016-2017 winter growing season, at the Harran University Agricultural Faculty Research Area. The field experiment was conducted to the Randomised Block Design, with 3 replications. The leaves length and width, the leaves number, the tuber number, the plant height, the flowers number and the glucomannan ratio were investigated. The plant height ranged between $9.71-24.33 \mathrm{~cm}$, the number of flowers ranged between 2.50-12.03 number plant ${ }^{-1}$, the number of leaves ranged between 2.105.16 number plant ${ }^{-1}$, the number of tuber ranged between 1.00-1.50 number plant ${ }^{-1}$, the average length of leaves ranged between $2.82-9.34 \mathrm{~cm}$, the average width of leaves ranged from 1.33-1.95 cm and the tuber yield ranged between 1.69-9.11 g plant ${ }^{-1}$ and the glucomannan ratio ranged between $28.60-59.63 \%$. The highest tuber yield was determined in Orchis sancta L. and the highest glucomannan ratio was determined in the Serapias vomeracea (Burm Fill.) Brig. For this reason, it can be suggested that these species may be cultivated under Şanlıurfa conditions.

Key Words: Orchidaceae, Salep Orchid, Salep, Glucomannan 


\section{Giriş}

Bitkisel gen kaynakları bakımından ülkemiz oldukça zengindir. Bu kaynakların, doğal florada kendiliğinden yetişebilmesi, sürekli var olacaklarmışçasına tüketilmelerine ve doğal ortamlarından alınarak tahrip edilmelerine sebep olmaktadır (Gümüş, 2009). Bu etkiye maruz kalan bitkilerin başında, şüphesiz, Orchidaceae türleri gelmektedir. Salep, Orchidaceae familyasında yer alan bir grup bitkiden elde edilir.

Orchidaceae familyası, tür sayısı bakımından dünyada bilinen en büyük ikinci familya olup, yaklaşık \%25'i karasal orkidelerden meydana gelmektedir. Familyaya ait yaklaşık, 600-800 cins ve 30.000-35.000 tür belirlenmiştir (Çığ, 2012; Parlak ve Tutar, 2014). Küçük Asya olarak adlandırılan Anadolu'da orkideler, 30'u endemik olmak üzere yetişebilen 170 tür ile benzersiz bir çeşitlilik sunar ve önemli bitkisel doğal kaynaklarımızdan biridir (Kreutz, 2009).

Ülkemiz Orchidaceae familyası taksonlarından 125 kadarı yumrulu olup bunlardan; Ophrys, Orchis, Himantoglossum, Anacamptis, Barlia, Serapias, Comperia, Dactylorhiza, Aceras, Neotinea cinslerine dahil, yaklaşık 100 tür salep elde etmek için toplanmaktadır. Bunlar içerisinde, Ophrys cinsi 60 türle, Orchis cinsi 30 türle ilk sıralarda yer almaktadır (Arslan 2012).

Salep elde edilen türlerin toprak altında genellikle, iki adet yumrusu bulunmakta ve bunlardan bir tanesi yeni oluşup şişerken, bir önceki yıl oluşan yumru buruşup, küçülmekte ve salep yapımında yeni oluşan yumru kullanılmaktadır (Sezik, 1984; Tekinşen, 2006). Yumrular genellikle, çiçeklenme döneminde toplanmakta, toplanan yumrular su ile iyice yıkanıp su, süt veya yoğurt ile 10-15 dakika kaynatılıp güneş altında kurutulduktan sonra, öğütülüp toz haline getirilerek, salep elde edilmektedir (Baytop, 1999).

Orkideler doğal ortamlarında iki türlü tahrip edilmektedirler. Bunlardan ilki, şiddetli yumru sökümü (doğrudan yok etme); ikincisi ise çiçeklenme döneminde yapılan söküm sebebiyle tohum oluşumunun engellenmesidir (dolaylı yok etme). Ayrıca, doğada oluşan tohumların çimlenmelerinin çok güç olması ve tohumdan oluşan bitkilerin gelişimlerinin uzun zaman alması, bu bitkilerin tahrip oranını daha da artmaktadır (Sandal, 2009).

Çok çeşitli amaçlarla kullanılan orkideler, Dünya'da gıda alanında, parfüm eldesinde ve tıbbi tedavilerde kullanılmaktadır. Ayrıca, süs bitkisi olarak da, orkideler bu sektörde değerli bir yere sahiptir. Ülkemizde ise orkide türlerinden elde edilen salep, asıl kullanım alanını oluşturmakta ve çok eski devirlerden beri bilinen, özellikle afrodizyak amaçlı kullanılan, bir ilaç olarak tanınmaktadır. İnsanlarda, mukoza zarını korumasından dolayı, solunum yollarının temizlenmesi, bronşit, mide ülseri gibi hastalıklarda yarar sağladığı da bilinmektedir. Bu amaçla ülkemiz doğasından her yıl en az, 10-20 milyon adet salep yumrusu toplanmaktadır (Sandal, 2009).

Salebin içerdiği ve tüketilmesine neden olan, en önemli madde glukomannan'dır (Sezik ve Özer, 1983). Salep, elde edildiği türe bağlı olarak, \%7-61 oranında glukomannan, \%8-19 oranında nişasta, \%0.5-1.5 azotlu maddeler, \%0.2-6 kül, \%1-4 şeker ve \%6-12 oranında nem içerir (Şen, 2016).

Yumrular yaş iken, 2-7 g olduğuna göre, ortalama $4 \mathrm{~g}$ olarak düşünülürse $1 \mathrm{~kg}$ taze yumru için 250 adet orkidenin sökülmesi gerekmektedir (Gümüş, 2009). Bir salep toplayıcısı normalde günde $1 \mathrm{~kg}$ taze yumru toplayabilmektedir. $1 \mathrm{~kg}$ salep üretmek için yaklaşık 1000-4000 yumruya intiyaç bulunmaktadır (Sezik, 1984). Bu durum salep üzerinde büyük bir baskı oluşturmaktadır.

İç tüketim ve ihraç potansiyeli yüksek bu bitkilerin, doğadan toplamak yerine, kültürü yapılması gerekmektedir. Bir bitkinin kültürünün yapılabilmesi için, o bitkinin tanınması, tarımını kısıtlayan yönlerin ve bu kısıtları ortadan kaldıracak teknikleri belirlenmesi gerekir. Bu amaçla öncelikle salep olarak kullanılabilen türlerin bazı bitkisel, tarımsal ve kalite özelliklerinin belirlenmesi ve bu konuda bilgi birikimi oluşturulması önemlidir.

Bu çalışmanın amacı, Şanlıurfa koşullarında 
yetişen bazı salep türlerinin bitkisel özelliklerini ve glukomannan içeriklerini belirlemektir.

\section{Materyal ve Yöntem}

$\mathrm{Bu}$ araştırmada salep yapımında kullanılan 5 tür (Ophrys lutea Cav., Serapias vomeracea (Burm. Fill.) Brig, Ophrys mammosa Desf., Ophrys umbilicata Desf. ve Orchis sancta L.) materyal olarak kullanılmıştır. Türler, Ege Tarımsal Araştırma Enstitüsünden temin edilmiştir. Çalışma, 2016-2017 kışlık ürün yetiştirme döneminde, Harran Üniversitesi Osmanbey Kampüsü, deneme alanında yürütülmüştür. Deneme alanı düz, düz yakın ağır tekstürlü topraklar olup, genelde derin, çok kireçli, kil tekstürlü, kuru koşullarda yazın çatlayan bir özelliğe sahip topraklardan oluşmaktadır.

Denemenin yürütüldüğü, Ekim-Mayıs aylarını kapsayan vejetasyon döneminde ortalama hava sıcaklığı, $5.4-22.9^{\circ} \mathrm{C}$ arasında olmuştur. Deneme yıllarında vejetasyon süresi boyunca, ortalama bağıl nem miktarı ise $\% 54.83$ olarak gerçekleşmiştir (Anonim, 2017).

Deneme, tesadüf blokları deneme desenine göre, 3 tekrarlamalı olarak yürütülmüştür. Denemede, 10-12 cm çevre uzunluğunda ve çiçek açma olgunluğuna sahip yumrular kullanılmıştır. Söz konusu yumrular dikime kadar, yaz boyunca $4{ }^{\circ} \mathrm{C}$ derecede saman dolu tahta kasalar içinde bekletilmiştir. Dikim öncesi yumrular koruma amaçlı olarak, toprak kökenli funguslara karşı, \%4'lük PROCHLORAZ CARBENDAZIM etken maddeli ve \%2'lik IPRODIONE etken maddeli fungusit solüsyonu içerisinde 10 dakika bekletilmiş ve serin, gölge bir alanda $10 \mathrm{~cm}$ 'yi geçmeyecek kalınlıkta, serilerek 2 gün kurutulmuştur. Deneme alanı dikimden önce bir kez sulanmış ve toprak tava geldiğinde, el traktörü ile sürüm yapılarak dikime hazır hale getirilmiştir. Kurutmanın ardından, yumrular her bir tür ayrı parselleri oluşturacak şekilde, 16.10.2016 tarihinde elle dikim yapılmıştır. Dikimler, $4 \mathrm{~m}$ boyun ve 5 sıradan oluşan parsellere, sıra arası 20 $\mathrm{cm}$, sıra üzeri $20 \mathrm{~cm}$ olacak şekilde ve $10 \mathrm{~cm}$ dikim derinliğinde elle yapılmıştır. Tüm Deneme alanına ayrıca, her parsele, dikim öncesi $25 \mathrm{~kg}$ siyah altın organik gübre verilmiştir. Yetiştirme sezonu boyunca dekara $1 \mathrm{~kg}$ olacak şekilde yapraktan 9.9.9 organik yaprak gübresi, sırt pülverizatörü ile verilmiştir. Deneme süresince gerektiğinde sulama, ot alma vb. bakım işlemleri yapılmıştır. Yumru hasadı, bitkilerin toprak üstü aksamları tam olarak kuruduğunda, türlere göre 25 Nisan tarihinden itibaren, bel yardımıyla, elle yapılmıştır. Araştırmada her bir parselde çıkış tarihi, çıkıs süresi, çiçeklenme tarihi, çiçeklenme süresi çiçeklenme periyodu ve vejetasyon süresi gibi fenolojik gözlemler ve glukomannan oranı ile birlikte, her bir tür için rastgele alınan 60 örnekte bitkisel gözlemler alınmıştır. Glukomannan oranı, Megazyme International Ireland Limited Şirketi tarafından üretilmiş olan Glucomannan Assay Kit (Catalogue Number: K-GLUM) kullanılarak Megazyme Glukomannan Deney Prosedürü (KGLUM 10/04) çerçevesinde hazırlanana örneklerde belirlenmiştir. Numunelerin glukomannan miktarları hazırlanan kör ve örnek solüsyonlara ait absorbans değerlerinin ( $A 1, A 2$, A3) UV-Vis Spektrofotometre'de $340 \mathrm{~nm}$ dalga boyunda ölçülmesi ve aşağıda belirtilen formüle eklenmesiyle hesaplanmıştır (Tekinşen ve ark., 2014; Şen, 2016).

$\triangle \mathrm{A}$ glukomannan $=(\mathrm{A} 3-\mathrm{A} 1)$ örnek $-(\mathrm{A} 3-\mathrm{A} 1)$ kör x 36.8 [g/100g]

Araştırmada elde edilen bitkisel özelliklerine ait veriler, Excel programında aritmetik ortalamaları ve standart sapmaları hesaplanmıştır. Glukomannan oranı verileri ise, Tesadüf blokları deneme desenine göre MSTAT-C ${ }^{\circledR}$ paket programı kullanılarak varyans analizine tabi tutulmuş ve LSD (\%5)'e göre gruplandırılmıştır.

\section{Araştırma Bulguları ve Tartışma}

\section{Fenolojik özellikler}

Bazı salep türlerin saptanan çıkış tarihi, çıkış süresi, çiçeklenme tarihi çiçeklenme süresi, çiçeklenme periyodu, vejetasyon süresi ile ilgili ortalama değerler Çizelge 1 'de verilmiştir. 
Çizelge 1. Türlere ilişkin fenolojik gözlemler

Table 1. Phenological observations of species

\begin{tabular}{|c|c|c|c|c|c|}
\hline $\begin{array}{l}\text { Türler } \\
\text { Species }\end{array}$ & Ophrys lutea & $\begin{array}{c}\text { Serapias } \\
\text { vomeracea }\end{array}$ & $\begin{array}{c}\text { Ophrys } \\
\text { mammosa }\end{array}$ & $\begin{array}{c}\text { Ophrys } \\
\text { umbilicata }\end{array}$ & Orchis sancta \\
\hline $\begin{array}{l}\text { Çıkış Tarihi } \\
\text { Release Date }\end{array}$ & 21.11.2016 & 21.11.2016 & 20.11.2016 & 22.11.2016 & 23.11.2017 \\
\hline $\begin{array}{l}\text { Çıkış süresi (gün) } \\
\text { Check-out time (days) }\end{array}$ & 49 & 49 & 48 & 50 & 51 \\
\hline $\begin{array}{l}\text { Çiçeklenme tarihi } \\
\text { Flowering date }\end{array}$ & 16.03.2017 & 04.04.2017 & 10.03.2017 & 10.03.2017 & 20.04.2017 \\
\hline $\begin{array}{l}\text { Çiçeklenme süresi (gün) } \\
\text { Flowering time (days) }\end{array}$ & 163 & 183 & 156 & 157 & 197 \\
\hline $\begin{array}{l}\text { Çiçeklenme periyodu (gün) } \\
\text { Flowering period (days) }\end{array}$ & 38 & 30 & 44 & 44 & 32 \\
\hline $\begin{array}{l}\text { Vejetasyon süresi (gün) } \\
\text { Vegetation season (day) }\end{array}$ & 209 & 218 & 199 & 197 & 233 \\
\hline
\end{tabular}

Çizelge 1'de, araştırmaya konu olan türlerde, çıkış tarihleri bakımından benzerlik olduğu ve genel olarak Kasım ayı sonunda gerçekleştiği görülmektedir. İlk çıkış yapan Ophyrs mammosa türüdür. Söz konusu bitkilerin, çıkış için benzer ekolojik koşullara ihtiyaç duydukları söylenebilir. Çıkış süreleri bakımından da türler benzerlik göstermiştir.

Çiçeklenme tarihlerinde ise, türler arasında bir farklılık olduğu gözlemlenmiştir. $\mathrm{Bu}$ durum bölgemizde hava sıcaklığı ve güneşlenme sürelerinin, Şubat ayından itibaren hızla artması (Anonim, 2017) ve türlerin bu duruma farklı tepki vermelerinden kaynaklanmış ve çiçeklenme de erken başlamıştır. En kısa çiçeklenme süresi, Ophyrs mammosa türünde, en kısa çiçeklenme periyodu ise, 30 gün ile Serapias vomeracea türünde saptanmıştır.

Çizelge 1'de görüldüğü gibi, araştırmaya konu olan türler arasında, vejetasyon süresi bakımından farklı sonuçlar elde edilmiştir. Bitkilerin vejetasyon süreleri dikkate alındığında, Ophyrs umbilicata türünün, en kısa sürede hasad olgunluğuna geldiği gözlemlenmiştir.

\section{Bitkisel özellikler}

Incelenen bazı özelliklerin ortalama değerleri Çizelge 2, Çizelge 3 ve Çizelge 4'te sunulmuştur.

Çizelge 2. Araştırmada incelenen bazı bitkisel özelliklere ilişkin ortalama ve standart sapma değerleri Table 2. Mean and standard deviation values for some plant characteristics investigated in the study

\begin{tabular}{|c|c|c|c|c|c|}
\hline $\begin{array}{c}\text { Türler } \\
\text { Species }\end{array}$ & Ophrys lutea & $\begin{array}{c}\text { Serapias } \\
\text { vomeracea }\end{array}$ & $\begin{array}{c}\text { Ophrys } \\
\text { mammosa }\end{array}$ & $\begin{array}{c}\text { Ophrys } \\
\text { umbilicata }\end{array}$ & Orchis sancta \\
\hline $\begin{array}{l}\text { Bitki boyu }(\mathrm{cm}) \\
\text { Plant length }(\mathrm{cm})\end{array}$ & $9.71 \pm 1.28$ & $24.33 \pm 5.70$ & $13.95 \pm 0.65$ & $14.35 \pm 0.63$ & $22.23 \pm 4.44$ \\
\hline $\begin{array}{l}\text { Bitki başına çiçek sayısı } \\
\text { (adet bitki }^{-1} \text { ) } \\
\text { Number of flowers per plant } \\
\text { (number plant }^{-1} \text { ) }\end{array}$ & $2.50 \pm 0.50$ & $4.37 \pm 1.44$ & $3.13 \pm 0.34$ & $2.32 \pm 0.47$ & $12.03 \pm 5.04$ \\
\hline $\begin{array}{l}\text { Bitkide yaprak sayısı } \\
\text { (adet bitki }^{-1} \text { ) } \\
\text { Number of leaf in the plant } \\
\text { (number plant }^{-1} \text { ) }\end{array}$ & $2.41 \pm 0.50$ & $3.50 \pm 0.70$ & $3.10 \pm 0.30$ & $2.10 \pm 0.30$ & $5.17 \pm 1.24$ \\
\hline $\begin{array}{l}\text { Yavru yumru sayısı (adet) } \\
\text { Number of Juvenile tubers } \\
\text { (number) }\end{array}$ & $1.20 \pm 0.40$ & $1.13 \pm 0.34$ & $1.00 \pm 0.00$ & $1.00 \pm 0.00$ & $1.50 \pm 0.54$ \\
\hline
\end{tabular}

\section{Bitki boyu}

Bitki boyu değerleri, $O$. lutea'da $9.71 \pm 1.28 \mathrm{~cm}$, S. vomeracea'da $24.33 \pm 5.70 \mathrm{~cm}, 0$. mammosa'da $13.95 \pm 0.65 \mathrm{~cm}$, O. umbilicata'da $14.35 \pm 0.63 \mathrm{~cm}$ ve $\quad$. sancta'da $22.23 \pm 4.44 \mathrm{~cm}$ olarak saptanmıştır (Çizelge 2). Ayrıca, denemeye konu olan türler arasında standart sapma değerleri farklılık göstermiş, $S$. vomeracea ve $O$. sancta türlerinde standart sapma değerleri oldukça yüksek bulunmuştur. Bu durum, türlerin genotipik 
ve bireysel gelişme performanslarının farklılıklarından kaynaklanabilir. O. lutea türünün bitki boyu değerlerinin Renz ve Taubenheim (1984) 7.00-30.00 cm, Durmuşkahya ve ark. (2014) 6.9-32.3 cm arasında değiştiğini bildirmişlerdir. Bulgularımız; bildirilen bu değerler aralığında ancak, Pellegrino ve ark. (2008) (18.00 $\mathrm{cm})$, Sandal (2009) $(10.00-30.00 \mathrm{~cm})$ bildirdikleri değerlerden daha düşüktür. $S$. vomeracea türünün bitki boyu değerlerini Renz ve Taubenheim (1984) 10.00-40.00 cm, Güler (2005) $10.00-46.00 \mathrm{~cm}$, Sandal (2009) $10.00-30.00 \mathrm{~cm}$ ve Arabacı ve ark. (2014) 15.62-31.33 cm olarak bildirmişlerdir. S. vomeracea türüne ilişkin değerlerimiz, bildirilen değerlerin arasındadır. $O$. mammosa türünün bitki boyu değerlerini Renz ve Taubenheim (1984) 20.00-50.00 cm, Aybeke (1997) $24.66 \pm 6.98 \mathrm{~cm}$, Güler (2005) 20.00-50.00 $\mathrm{cm}$, Tığlı (2015) $15.25-18.02 \mathrm{~cm}$ ve Merdamert ve ark. (2015) $23.8 \mathrm{~cm}$ olarak bildirmişlerdir. $O$. mammosa türüne ilişkin değerlerimiz, bildirilen değerlerin altında yer almıştır. O. umbilicata türünün bitki boyu değerlerini Renz ve Taubenheim (1984) 20.00-50.00 cm ve İşler (2005) $25.00 \mathrm{~cm}$ olarak bildirmişlerdir. Bildirilen bu değerler bulgularımızdan daha yüksek ancak Sandal (2009)'ın bildirmiş olduğu değerler (10.00$30.00 \mathrm{~cm}$ ) arasındadır. O. sancta türüne ilişkin saptadığımız bitki boyu değerleri Renz ve Taubenheim (1984) (20.00-60.00 cm), Güler (2005) (19.50-48.00 cm) ve Arabacı ve ark. (2014) (16.82-24.56 cm)'nın bildirmiş olduğu değerler arasında olup, Sevgi ve ark. (2012) (36.50-52.00 $\mathrm{cm}$ )'nın bildirdikleri değerlerden daha düşüktür. Bitki boyuna ilişkin değerlerimizle literatürlerde bildirilen değerler arasındaki bu farklılık; genotipik farklılıktan, ekolojik koşullardan ve yetiştirme tekniği farklılıklarından kaynaklanabilir. Örneğin doğal ortamı daha çok orman altı, kaya gölgesi olan bu bitkiler, doğal ortamda daha az ışıklı alanlarda yetiştiklerinden, bitki boyları daha uzun olacaktır. Ayrıca bölgemizde sıcakların erken başlaması bitkilerin daha erken dönemde generatif devreye geçmeye zorlamış ve bu durum bitki boylarının daha kısa kalmasına neden olmuştur.
Bitki başına çiçek sayısı

Denemeye konu olan türlerde çiçek sayısı değerleri, $O$. lutea'da $2.50 \pm 0.50$ adet bitki ${ }^{-1}, S$. vomeracea'da $4.37 \pm 1.44$ adet bitki ${ }^{-1}, \quad O$. mammosa'da $3.13 \pm 0.34$ adet bitki ${ }^{-1}, \quad O$. umbilicata $^{\prime}$ da $2.32 \pm 0.47$ adet bitki ${ }^{-1}$ ve $O$. sancta'da $12.03 \pm 5.04$ adet bitki $^{-1}$ olarak saptanmıştır. Çiçek sayısı ortalamalarına göre, $S$. vomeracea, $O$. mammosa ve $O$. sancta türlerinde üçten fazla çiçek saptanırken $O$. lutea ve $O$. umbilicata türlerinde üçten düşük olarak saptanmıştır (Çizelge 2).

\section{Bitkide yaprak sayısı}

Denemeye konu olan tüm türlerde, yaprak sayısı türlere göre, $O$. lutea'da $2.41 \pm 0.50$ adet bitki $^{-1}$, S. vomeracea'da $3.50 \pm 0.70$ adet bitki ${ }^{-1}, O$. mammosa'da $3.10 \pm 0.30$ adet bitki ${ }^{-1}, \quad O$. umbilicata $^{\prime}$ da $2.10 \pm 0.30$ adet bitki ${ }^{-1}$, ve 0 . sancta'da $5.17 \pm 1.24$ adet bitki ${ }^{-1}$, olarak saptanmıştır. O. lutea türünün yaprak sayısı değerlerini, Renz ve Taubenheim (1984) 3.00-5.00 adet, Güler (2005) 4.00-8.00 adet ve Sandal (2009) 4.00-9.00 adet olarak bildirmişlerdir. Bildirilen değerler bulgularımızdan yüksek, ancak Durmuşkahya ve ark. (2014) (2.00-6.00 adet)'nın bildirdikleri değerler arasında yer almıştır. $S$. vomeracea türünün yaprak sayısı değerlerini, Güler (2005) 4.00-9.00 adet ve Sandal (2009) 4.00-6.00 adet olarak bildirmişlerdir. Bildirilen değerler bulgularımızdan yüksek, ancak Durmuşkahya ve ark. (2014) (2.00-6.00 adet)'nın bildirdikleri değerler arasında yer almıştır. $O$. mammosa türünün yaprak sayısı değerini, Renz ve Taubenheim (1984) ve Güler (2005) 3.00-6.00 adet arasında bildirmişlerdir. Bildirilen değerler arasında olup ancak Aybeke (1997) (5.00-9.00 adet) ve Sandal (2009) (4.00-9.00 adet)'nın bildirdikleri değerlerden daha düşük çıkmıştır. $O$. umbilicata türünün yaprak sayısı değerlerini, Renz ve Taubenheim (1984) (3.00-7.00 adet), Güler (2005) (4.00-8.00 adet), İşler (2005) (6.00 adet), Sandal (2009) (3.00-7.00 adet) olarak bildirmişlerdir. Bildirilen değerler bulgularımızdan yüksek, ancak Durmuşkahya ve ark. (2014) (2.006.00 adet)'nın bildirdikleri değerler arasında yer 
almıştır. O. sancta türünün yaprak sayısı değerlerini, Güler (2005) (4.00-8.00 adet, Sandal (2009) 4.00-9.00 adet ve Durmuşkahya ve ark. (2014) 2.00-6.00 adet olarak bildirmişlerdir. Bulgularımız bildirilen değerler arasında olup ancak, Renz ve Taubenheim (1984) (3.00-5.00 adet)'nın bildirdikleri değerlerden yüksektir. Yaprak sayısına ilişkin değerlerimiz ile literatürlerde bildirilen değerler arasındaki bu farklılık; genotipik farklılıktan, ekolojik koşullardan ve yetiştirme tekniği farklılıklarından kaynaklanmışolabilir.

\section{Yavru yumru sayısı}

Yavru yumru sayısı değerleri, O. lutea'da $1.20 \pm 0.40$ adet bitki ${ }^{-1}$, S. vomeracea' da $1.13 \pm 0.34$ adet bitki ${ }^{-1}, O$. mammosa' da $1.00 \pm 0.00$ adet bitki ${ }^{1}$, O. umbilicata' da $1.00 \pm 0.00$ adet bitki ${ }^{-1}$ ve $O$. sancta'da $1.50 \pm 0.54$ adet bitki ${ }^{-1}$ olarak saptanmıştır. Türler arasında en düşük yavru yumru sayısı $O$. mammosa ve $O$. umbilicata'da, en yüksek yavru yumru sayısı $O$. sancta'da saptanmıştır (Çizelge 2).

Çizelge 3. Bazı bitkisel özelliklere ilişkin ortalama ve standart sapma değerleri

Table 3. Mean and standard deviation values for some plant characteristics

\begin{tabular}{|c|c|c|c|c|c|}
\hline $\begin{array}{c}\text { Türler } \\
\text { Species }\end{array}$ & $\begin{array}{l}\text { Ophrys } \\
\text { lutea }\end{array}$ & $\begin{array}{c}\text { Serapias } \\
\text { vomeracea }\end{array}$ & $\begin{array}{l}\text { Ophrys } \\
\text { mammosa }\end{array}$ & $\begin{array}{c}\text { Ophrys } \\
\text { umbilicata }\end{array}$ & Orchis sancta \\
\hline $\begin{array}{l}\text { Yaprak boyu }(\mathrm{cm}) \\
\text { Leaf length }(\mathrm{cm})\end{array}$ & $3.61 \pm 0.72$ & $9.34 \pm 1.10$ & $4.80 \pm 0.40$ & $2.82 \pm 0.62$ & $5.49 \pm 1.08$ \\
\hline $\begin{array}{l}\text { Yaprak eni }(\mathrm{cm}) \\
\text { Leaf width }(\mathrm{cm})\end{array}$ & $1.47 \pm 0.10$ & $1.78 \pm 0.14$ & $1.96 \pm 0.07$ & $1.34 \pm 0.06$ & $1.45 \pm 0.19$ \\
\hline $\begin{array}{l}\text { Bitki başına yumru verimi }\left(\mathrm{g} \mathrm{bitki}^{-1}\right) \\
\text { Tubers yield per plant }\left(\mathrm{g} \text { plant }^{-1}\right)\end{array}$ & $1.69 \pm 0.19$ & $5.30 \pm 0.25$ & $1.89 \pm 0.13$ & $2.10 \pm 0.18$ & $9.11 \pm 0.17$ \\
\hline
\end{tabular}

\section{Yaprak boyu}

Ortalama yaprak boyu değerleri, O. lutea'da $3.61 \pm 0.72 \mathrm{~cm}, S$. vomeracea $9.34 \pm 1.10 \mathrm{~cm}, O$. mammosa'da $4.80 \pm 0.40 \mathrm{~cm}, O$. umbilicata' da $2.82 \pm 0.62 \mathrm{~cm}$ ve 0 . sancta'da $5.49 \pm 1.08 \mathrm{~cm}$ olarak saptanmıştır. Denemeye konu olan $S$. vomeracea ve $O$. sancta türlerinde standart sapma değerleri oldukça yüksek bulunmuştur (Çizelge 3). O. lutea türünün yaprak boyu değerlerini, Güler (2005) 3.5-9.0 cm, Durmuşkahya ve ark. (2014) 2.1-5.5 cm ve Merdamert ve ark. (2015) $4.34 \mathrm{~cm}$ olarak bildirmişlerdir. $O$. lutea türüne ilişkin değerlerimiz, bildirilen değerler arasında yer almıştır. S. vomeracea türünün yaprak boyu değerini, Güler (2005) 4.5-17.0 cm olarak bildirmiştir. $S$. vomeracea türüne ilişkin değerlerimiz, bildirilen değerin üst sınırından düşük, alt sınırının üstünde yer almıştır. $O$. mammosa türünün yaprak boyu değeri, Durmuşkahya ve ark. (2014) (2.1-5.5 cm)'nın bildirdiği değerler arasında olup ancak, Aybeke (1997) $(6.72 \mathrm{~cm})$, Güler (2005) (5.00-11.00 cm)'in bildirdiği değerlerden düşük, Merdamert ve ark.
(2015) $(4.34 \mathrm{~cm}$ )'nın bildirdiği değerlerden ise yüksektir. O. umbilicata türünün yaprak boyu değeri, Bozyel ve ark. (2017) (1.5-6.2 cm)'nın bildirdiği değerler arasında olup ancak, İşler (2005) (4.00-15.00 cm)'in bildirdiği değerlerden düşüktür. $O$. sancta türünün yaprak boyu değeri, Güler (2005) (5.5-12.00 cm), Sevgi ve ark. (2012) (4.0-9.2 cm)'nın bildirdiği değerler arasında olup ancak, Renz ve Taubenheim (1984) (8.00-15.00 $\mathrm{cm}$ )'nin bildirdiği değerlerin altında yer almıştır. Yaprak boyuna ilişkin değerlerimizle literatürlerde bildirilen değerler arasındaki bu farklılık; genotipik farklılıktan, ekolojik koşullardan ve yetiştirme tekniği farklııılarından kaynaklanabilir.

\section{Yaprak eni}

Ortalama yaprak eni değerleri, O. lutea'da $1.47 \pm 0.10 \mathrm{~cm}, S$. vomeracea $1.78 \pm 0.14 \mathrm{~cm}, O$. mammosa'da $1.96 \pm 0.07 \mathrm{~cm}, 0$. umbilicata'da $1.34 \pm 0.06 \mathrm{~cm}$ ve 0 . sancta'da $1.45 \pm 0.19 \mathrm{~cm}$ olarak saptanmıştır (Çizelge 3). O. lutea türünün yaprak eni değeri, Güler (2005) (1.1-2.5 cm)'in bildirdiği değerler arasında olup ancak Durmuşkahya ve ark. (2014) (0.9-1.4 cm)'nın 
bildirdiği değerlerden yüksek, Merdamert ve ark. (2015) $(1.73 \mathrm{~cm}$ )'nın bildirdiği değerlerden ise düşüktür. S. vomeracea türünün yaprak eni değerini, Güler (2005) 0.6-2.0 cm olduğunu bildirmiştir. S. vomeracea türüne ilişkin değerlerimiz, bildirilen bu değerlerin arasında yer almıştır. O. mammosa türünün yaprak eni değeri, Güler (2005) (1.8-2.5 cm)'in bildirdiği değerler arasında olup ancak, Aybeke (1997) $(1.21 \mathrm{~cm})$ ve Durmuşkahya ve ark. (2014) (0.9-1.4 cm)'nın bildirdiği değerlerden yüksek, Merdamet ve ark. (2015) $(2.19 \mathrm{~cm}$ )'nın bildirdiği değerden düşüktür. O. umbilicata türünün yaprak eni değerini, İşler (2005) 1.5-3.5 cm ve Bozyel ve ark. (2017) 1.7-3.5 $\mathrm{cm}$ olarak bildirilmiştir. O. umbilicata türüne ilişkin değerlerimiz, bildirilen değerlerin üst sınırlarından düşük, alt sınırlarının üstünde yer almıştır. O. sancta türünün yaprak eni değeri, Renz ve Taubenheim (1984) (0.5-1.5 cm) ve Güler (2005) (0.70-1.60 cm)'in bildirdiği değerler arasında olup ancak, Sevgi ve ark. (2012) (1.5$2.00 \mathrm{~cm}$ )'nın bildirdiği değerlerden düşüktür. Yaprak enine ilişkin değerlerimizle literatürlerde bildirilen değerler arasındaki bu farklılık; genotipik farklılıktan, ekolojik koşullardan ve yetiştirme tekniği farklııklarından kaynaklanabilir.

\section{Bitki başına yumru verimi}

Ortalama yumru verimi değerleri, O. Iutea'da $1.69 \pm 0.19 \mathrm{~g} \mathrm{bitki}^{-1}$, S. vomeracea $5.30 \pm 0.25 \mathrm{~g} \mathrm{bitki}^{-}$ 1 , O. mammosa'da $1.89 \pm 0.13 \mathrm{~g}$ bitki $^{-1}, \quad 0$. umbilicata'da $2.10 \pm 0.18 \mathrm{~g} \mathrm{bitki}^{-1}$ ve $O$. sancta'da $9.11 \pm 0.17 \mathrm{~g} \mathrm{bitki}^{-1}$ olarak saptanmıştır (Çizelge 3). Yavru sayısı değeri ile yumru verimi değerleri arasında bir paralellik gözlenmiştir (Çizelge 2). S. vomeracea türünün bitki başına yumru verimi değerini, Tutar (2011) 2.40-5.90 $\mathrm{g} \mathrm{bitki}^{-1}$ ve Arabacı ve ark. (2014) 2.48-5.89 $\mathrm{g} \mathrm{bitki}^{-1}$ olarak bildirmişlerdir. S. vomeracea türüne ilişkin değerlerimiz, bildirilen değerler arasında yer almıştır. O. mammosa türünün bitki başına yumru verimi değeri, Tığlı (2015) tarafından 0.21-3.30 g bitki $^{-1}$ olarak bildirilmiştir. O. mammosa türüne ilişkin değerlerimiz, bildirilen değerlerin üst sınırlarından düşük ve alt sınırlarının üstünde yer almıştır. $O$. sancta türünün bitki başına yumru verimi değerini, Tutar (2011) (5.1-9.4 g bitki $\left.{ }^{-1}\right)^{\prime} ı n$ bildirdiği değerler arasında olup ancak Parlak ve ark. (2014) (2.26-2.75 $\left.\mathrm{g} \mathrm{bitki}^{-1}\right)$, Arabacl ve ark. (2014) (0.78-2.89 g bitki $\left.{ }^{-1}\right)^{\prime} n ı n$ bildirdiği değerlerden yüksek olmuştur. Bitki başına yumru verimine ilişkin değerlerimizle literatürlerde bildirilen değerler arasındaki bu farklılık; genotipik farklılıktan, ekolojik koşullardan, yetiştirme tekniği farklılıklarından ve kaynaklanmış olabilir.

Çizelge 4. Türlere göre glukomannan değerleri Table 4. The glucomannan ratio of species

\begin{tabular}{lc}
\multicolumn{1}{c}{ Table 4. The glucomannan ratio of species } \\
\multicolumn{1}{c}{ Species } & $\begin{array}{c}\text { Glukomannan oranı (\%) } \\
\text { Glucomannan ratio (\%) }\end{array}$ \\
\hline $\begin{array}{l}\text { Ophrys lutea Cav. } \\
\text { Serapias vomeracea (Burm. }\end{array}$ & $30.13 \mathrm{~b}$ \\
fill.) Brig. & $59.63 \mathrm{a}$ \\
Ophrys mammosa Desf. & $28.60 \mathrm{~d}$ \\
Ophrys umbilicata Desf. & $30.17 \mathrm{~b}$ \\
Orchis sancta L. & $29.47 \mathrm{c}$ \\
\hline Ortalama & 35.60 \\
Average & 0.386 \\
\hline LSD (\%5) &
\end{tabular}

\section{Glukomannan oranı}

Türler arasında glukomannan oranı değerleri, O. lutea $\% 30.13$, S. vomeracea $\% 59.63,0$. mammosa $\% 28.60,0$. umbilicata $\% 30.17$ ve 0 . sancta \%29.47 ve türler arasında ortalama glukomannan oranı \%35.60 olarak saptanmıştır (Çizelge 4). S. vomeracea türünün glukomannan oranı, Şen (2016) tarafından \%47.36 olarak bildirmiştir. S. vomeracea türüne ilişkin değerimiz, bildirilen değerin üstünde yer almıştır. $O$. mammosa türünün glukomannan oranını, Tekinşen ve ark. (2009) \%17.67 olarak bildirmişlerdir. $O$. mammosa türüne ilişkin saptadığımız değerler, bildirilen değerin üstünde yer almıştır. Şen (2016) O. sancta türünün glukomannan oranını, \%17.41 olarak bildirmiştir. O. sancta türüne ilişkin değerlerimiz, bildirilen değerin üstünde yer almıştır.

\section{Sonuçlar}

Türkiye florasında belli bölgelerde yaygın olarak bulunan ancak, doğadan toplama baskısı ve ekosistemleri üzerindeki tahribatı altında, yok olma tehlikesi taşıyan salep bitkisi, tarımsal açıdan önem taşıyan morfolojik ve fenolojik özelliklerinin büyük bir varyasyon ortaya koyduğu görülmüştür. Ayrıca genel olarak, Şanlıurfa 
koşullarında türlerin glukomannan oranlarının literatürde bildirilen değerlerden yüksek olduğu saptanmıştır.

Glukomannan oranı (\%59.63) bakımından yüksek değerlere ulaşan Serapias vomeracea ( Burm. Fill.) Brig. türü ile, yavru yumru sayısı ve bitki başına yumru verimi (9.11 g/bitki) bakımından yüksek değerlere ulaşan Orchis sancta L. türünün Şanlıurfa koşullarında yetiştirilebilme potansiyeline sahip oldukları anlaşılmıştır. Öncelikle bu türlerle ilgili bilgi birikimi oluşturmak üzere, temel yetiştirme tekniklerinin belirlenmesi ve standart ürün ve üründe devamlılık sağlamak için, ıslah çalışmalarının yapılmasına gereksinim vardır.

\section{Ekler}

Bu makale, HÜBAK tarafından desteklenen (Proje No: 16159), Yüksek Lisans Tezinden hazırlanmıştır.

\section{Kaynaklar}

Anonim, (2017). Meteoroloji Genel Müdürlüğü.

Arabacı, O., Tutar, M., Özcan, i. i.,, Öğretmen, N. G., \& Yıldız, Ö. (2014). Salep orkidelerinden Orchis sancta L. türünün tarla koşullarında hasat zamanının belirlenmesi. II. Tıbbi ve Aromatik Bitkiler Sempozyumu. 23-25 Eylül, Bildiriler Kitabı, Yalova, s.473-478.

Arslan, N. (2012). Salep orkidelerinin yetiştirilmesinde yeni bir ümit: salebin yumrudan üretimi. Sağlık Çevre Kültürü Dergisi, 6, 20-22.

Aybeke, M. (1997). Edirne çevresindeki Ophrys L. (Orchidaceae) türleri üzerinde morfolojik, karyolojik ve palinolojik araştırmalar. Trakya Üniversitesi, Fen Bilimleri Enstitüsü, Yüksek Lisans Tezi, Edirne, 122s.

Baytop, T. (1999). Türkiye'de bitkiler ile tedavi. İstanbul Üniversitesi Eczacılık Fakültesi, Yayın No: 3255/40, İstanbul. s.325-327.

Bozyel, M. E., \& Gönüz, A. (2017). Vegetative anatomy and morphology of Ophrys lutea ssp. minör in Çanakkale. Interactive conservation platform for orchids native to Greece and Turkey (ICON) International Final Conference, 18-21 Nisan, Antalya, s.34.

Çı̆̆, A. (2012). Van'da doğal olarak yetişen salep orkidelerinin simbiyotik ve asimbiyotik olarak in vitro ve in vivo ortamlarda çoğaltılması. Yüzüncü Yıl Üniversitesi, Fen Bilimleri Enstitüsü, Doktora Tezi, Van, 162s.

Durmuşkahya, C., Özdemir, C., Bozdağ, B., \& Öztürk M. (2014). Studies on the morphology, anatomy and ecology of Ophrys lutea Cav. subsp. minor (Guss.) 0. Danesch \& E. Danesch ex Gölz \& H.R. Reinhard (Orchidaceae) in Turkey. Pak. J. Bot., 46(2),565-571.

Güler, N. (2005). Kazdağları'ında yetişen Orchidaceae familyası bitkileri üzerinde morfolojik ve korolojik araştırmalar. Trakya Üniversitesi, Fen Bilimleri Enstitüsü, Doktora Tezi, Tekirdağ, 265s.

Gümüş, C. (2009). Batı Karadeniz Bölgesi'nde salep elde edilmesinde kullanılan bazı orkide türlerinin (Orchidaceae) çoğaltım yöntemleri üzerinde araştırmalar. Ankara Üniversitesi, Fen Bilimleri Enstitüsü, Doktora Tezi, Ankara, 221s.

İşler, S. (2005). Van salebinin menşei ve Van civarının orkideleri. Doktora Tezi, Yüzüncü Yıl Üniversitesi, Fen Bilimleri Ens., Van.

Kreutz, K. (2009). Türkiye orkideleri; botanik özellikleri, ekolojik istekleri, doğal yayılış alanları, yaşam tehditleri, koruma önlemleri. Editör, Yazar ve Çevirmen Doç. Dr. Alper ÇOLAK, Rota Yayınları, ISBN: 976-605-4015-07-8.

Merdamert, E., Bozyel M. E., Yılmaz, M., \& Gönüz A. (2015). Gökçeada (Çanakkale) doğal yayılışlı üç Ophrys (Orchidaceae) taksonunun anatomik ve morfolojik özelliklerinin incelenmesi. 1. Ulusal Bitki Biyolojisi Kongresi, 2-4 Eylül, Bildiri Kitabı, Bolu, s.216.

Parlak, S., \& Tutar, M. (2014). Anacamptis sancta salep orkidesinde yaprak gübresi uygulamasının yumru iriliğine etkisi. III. Uluslararası Odun Dışı Orman Ürünleri Sempozyumu, 8-10 Mayıs, Bildiriler Kitabı, Kahramanmaraş, s.1-6.

Pellegrino, G., Bellusci, F., \& Musacchio, A. (2008). Morphological and molecular, investigation of the parentage of Ophrys $\times$ Circlarium (O. lutea $\times 0$. tarentina), a new hybrid orchid from Italy. Ann. Bot. Fennici, 45, 61-67.

Renz, J., \& Taubenheim, G. (1984). Orchidaceae. In PH Davis, ed, The Flora of Turkey and the East Aegean Islands, Vol 8, Edinburgh University Press, Edinburgh.

Sandal, G. (2009). Doğu Akdeniz Bölgesi'nde yetişen orkideler ve yetişme ortamı nitelikleri ile tehdit faktörlerinin araştırılması. Çukurova Üniversitesi, Fen Bilimleri Enstitüsü, Doktora tezi, Adana, 210s.

Sevgi, E., Altundağ, E., Kara, Ö., Sevgi, O., Tecimen, H. B., \& Bolat, í. (2012). Morphological and ecological studies on some orchis (Orchidaceae) taxa of Mediterranean Region in Turkey. J. Environ. Biol., 33, 343-353.

Sezik, E., \& Özer, B. (1983). Kastamonu Salebinin Menşei ve Kastamonu Civarının Orkideleri. TÜBITAK Proje No: TBAG-424, Ankara.

Sezik, E. (1984). Orkidelerimiz. Sandoz Kültür Yayınları, No:6 İstanbul s.1-166.

Şen, M. A. (2016). Türkiye'nin değişik yörelerinden toplanan orkidelerden elde edilen saleplerin özelliklerinin belirlenmesi ve geleneksel yöntemle Maraş usulü dondurma yapımında ürün kalitesine etkilerinin araştırılması. Namık Kemal Üniversitesi, Fen Bilimleri Enstitüsü, Doktora Tezi, Tekirdağ, 146s.

Tekinşen, K. K. (2006). Salep. Bilim ve Teknik, TüBiTAK Aylık Popüler Bilim Dergisi, Haziran, 453, 76-77.

Tekinşen, K.K., \& Güner, A. (2009). Kahramanmaraş yöresinde yetişen saleplerin kimyasal bileşiminin ve bazı fizikokimyasal niteliklerinin araştırılması. Selçuk Üniversitesi Bilimsel Araştırma Projeleri, Proje No: 06401061, Konya.

Tığlı. E. H. (2015). Bucak (Burdur) yöresinde bazı doğal orkide türlerinin yayılış alanları, morfolojik ve fenolojik özellikleri. Süleyman Demirel Üniversitesi, Fen Bilimleri Enstitüsü, Doktora Tezi, Isparta, 164s.

Tutar, M. (2011). Ege Bölgesi salep orkidelerinde üretim olanaklarının araştırılması. Proje no: TAGEM/TA/07/05//04/003. 